\title{
A U5 repressor of reverse transcription is required for optimal HIV-I infectivity and replication
} Luke Meredith ${ }^{1,2}$, Céline Ducloux ${ }^{3}$, Catherine Isel $^{3}$, Roland Marquet ${ }^{3}$ and David Harrich*1,2

Address: ${ }^{1}$ Griffith Medical Research College, a joint program of Griffith University and the Queensland Institute of Medica' esearch, QIM $R$, Herston, QLD, Australia, 4006, ${ }^{2}$ Queensland Institute of Medical Research, Royal Brisbane Hospital Post Office, Brisbane402 ${ }^{3}$ Architecture et Réactivité de l'ARN, Université de Strasbourg, CNRS, IBMC, 15 rue René Descartes, 67084 Strasbouro, cedex, Fr

* Corresponding author

from Frontiers of Retrovirology: Complex retroviruses, retroelements and their hosts Montpellier, France. 21-23 September 2009

Published: 24 September 2009

Retrovirology 2009, 6(Suppl 2):OI4 doi:I0.II86/I742-4690-6-S2-OI4

This abstract is available from: http://www.retrovirology.com/content/6/S2/OI4

(c) 2009 Meredith et al; licensee BioMed Central Ltd.

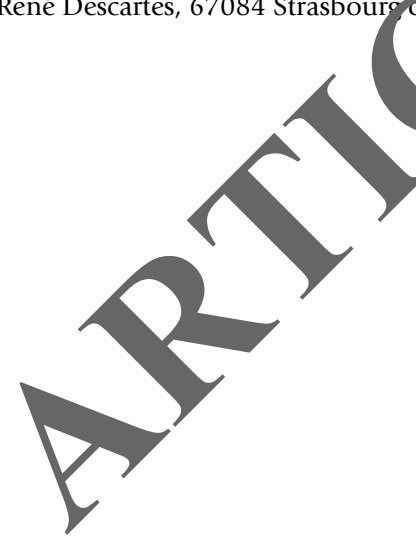

Here we provide strong evidence that a highly con ve' stem loop structure in the U5 region of the $\mathrm{H} N \mathrm{~N}$ leader harbours a repressor of reverse transcriv $n$ (RRT) co, nplex, which also protects the proviral DNA from celWe showed that two sequences in U5, at $+143-5$ and $+151-153$, are essential for RRT functon. Mutati $n$ of either site strongly and unexpectedly increased endogenous reverse transcription, and cel infection assays showed that both mutations dra atically mcreased negative strand strong stop DNA syniticy arly, late, 1-LTR and 2-LTR reverse transc tion roducts were present proportionally, indicat ig $t$ at thy/downstream reverse transcription events wer or arrected. In vitro structural probing of the y type a $/$ mutant RNA revealed an unexpected des abi tion effect of the mutations on the whole U5 st Am loop, $\mathrm{w}$ ch would explain the loss of regulation $o$ ve se transcription. This functional effect was not observe $\eta v i$, where, in the absence of viral proteipso er th, RT and cellular factors, all RNA perfor d arly. These U5 mutations decreased virus replio on in Jurkat and primary T-cells, which could be attribut d to a marked defect in viral integration. Analysis of 1-LTR and 2-LTR circular DNA isolated from infected cells revealed that substantial deletions were present, indicating that the viral DNA was degraded by cellular nucleases. Together, our experiments suggest that regulated reverse transcription initiation is essential to allow synthesis of the viral DNA in a cellular environment that supports the assembly of a functional HIV-1 pre-integration 